Arq. Bras. Med. Vet. Zootec., v.61, supl. 1, p.35-45, 2009

\title{
Situação epidemiológica da brucelose bovina no Estado de Minas Gerais
}

[Epidemiological status of bovine brucellosis in the State of Minas Gerais, Brazil]

\author{
V.S.P. Gonçalves ${ }^{1}$, M.K.V.C. Delphino ${ }^{1}$, R.A. Dias ${ }^{2}$, F. Ferreira ${ }^{2}$, M. Amaku ${ }^{2}$, J.S. Ferreira Neto ${ }^{2}$, \\ T.B. Porto ${ }^{3}$, C.M. Alves ${ }^{4}$, V.C.F. Figueiredo ${ }^{5}$, J.R. Lôbo ${ }^{5}$ \\ ${ }^{1}$ Faculdade de Agronomia e Medicina Veterinária - UnB \\ Caixa Postal 4508 \\ 70910-970 - Brasília, DF \\ ${ }^{2}$ Faculdade de Medicina Veterinária e Zootecnia - USP - São Paulo, SP \\ ${ }^{3}$ Instituto Mineiro de Agropecuária - Belo Horizonte, MG \\ ${ }^{4}$ Superintendência Federal de Agricultura - MAPA - Belo Horizonte, MG \\ ${ }^{5}$ Departamento de Saúde Animal-SDA-MAPA - Brasília, DF
}

\begin{abstract}
RESUMO
Realizou-se um estudo para caracterizar a situação epidemiológica da brucelose bovina no Estado de Minas Gerais. O Estado foi estratificado em sete circuitos produtores. Em cada circuito foram amostradas aleatoriamente cerca de 300 propriedades e, dentro dessas, foi escolhido, de forma aleatória, um número pré-estabelecido de animais, dos quais foi obtida uma amostra de sangue. No total, foram amostrados 20.643 animais, provenientes de 2.204 propriedades. Em cada propriedade visitada aplicou-se um questionário epidemiológico para verificar o tipo de exploração e as práticas zootécnicas e sanitárias que poderiam estar associadas ao risco de infecção pela doença. O protocolo de testes utilizado foi o da triagem com o teste do antígeno acidificado tamponado e a confirmação dos positivos com o teste do 2mercaptoetanol. $\mathrm{O}$ rebanho foi considerado positivo, se pelo menos um animal foi reagente às duas provas sorológicas. As prevalências de focos e de animais infectados do Estado foram de 6,0\% [5,0-7,1\%] e $1,1 \%[0,78-1,4 \%]$, respectivamente. Os resultados para os circuitos pecuários da prevalência de focos e de animais foram: circuito $1,4,7 \%[2,7-7,7 \%]$ e $0,82 \%$ [0,06-1,6\%]; circuito $2,7,2 \%$ [4,6-10,6\%] e $1,2 \%$ [0,53-1,8\%]; circuito 3, 6,8\% [4,3-10,0\%] e $1,5 \%$ [0,47-2,4\%]; circuito $4,6,5 \%$ [4,1-9,8\%] e $1,1 \%$ [0,39-1,7\%]; circuito $5,3,8 \%$ [2,0-6,5\%] e $0,40 \%$ [0,11-0,69\%]; circuito $6,6,2 \%$ [3,8-9,6\%] e $0,66 \%$ $[0,29-1,0 \%]$; circuito $7,11,0 \%[7,7-15,0 \%]$ e $1,7 \%[0,92-2,6 \%]$, respectivamente. Os fatores de risco (odds ratio, $\mathrm{OR}$ ) associados à condição de foco foram: compra de reprodutores $(\mathrm{OR}=1,66[1,13-2,44])$, ocorrência de aborto nos últimos 12 meses $(\mathrm{OR}=1,81[1,26-2,60])$ e presença de cervídeos na propriedade $(\mathrm{OR}=1,56[1,08-2,27])$. A vacinação contra brucelose foi identificada como fator protetor $(\mathrm{OR}=0,38[0,19-0,79])$. Concluiu-se que o programa obrigatório de vacinação de bezerras, iniciado na década de 1990, está sendo eficaz ao reduzir a prevalência em todo o Estado e em todos os sistemas de produção animal. As autoridades sanitárias devem priorizar o controle da compra de animais para reprodução, que não apresentem garantias sanitárias e incorporar essa medida às ações de educativas.
\end{abstract}

Palavras-chave: bovino, brucelose, prevalência, fatores de risco, Minas Gerais

\begin{abstract}
A study to characterize the epidemiological status of brucellosis was carried out in the State of Minas Gerais. The State was divided in seven regions. Three hundred herds were randomly sampled in each region and a pre-established number of animals was sampled in each of these herds. A total of 20,643 serum samples from 2,204 herds were collected. In each herd, it was applied an epidemiological questionnaire focused on herd traits as well as husbandry and sanitary practices that could be associated with the risk of infection. The serum samples were screened for antibodies against Brucella spp. by the
\end{abstract}

Recebido em 27 de março de 2009

Aceito em 23 de setembro de 2009

E-mail: vitorspg@unb.br 
Rose-Bengal Test (RBT), and all positive sera were re-tested by the 2-mercaptoethanol test (2-ME). The herd was considered positive if at least one animal was positive on both RBT and 2-ME tests. The prevalence of infected herds and animals in the State were, respectively, 6.0\% [5.0-7.1\%] and 1.1\% [0.78-1.4\%]. In the productive regions, the prevalence of infected herds and animals were, respectively: regions $1,4.7 \%$ [2.7-7.7\%] and $0.82 \%$ [0.06-1.6\%]; region 2, 7.2\% [4.6-10.6\%] and $1.2 \%[0.53-$ $1.8 \%]$; region 3, $6.8 \%$ [4.3-10.0\%] and 1.5\% [0.47-2.4\%]; region 4, 6.5\% [4.1-9.8\%] and $1.1 \%[0.39$ $1.7 \%]$; region 5, 3.8\% [2.0-6.5\%] and 0.40\% [0.11-0.69\%]; region 6, 6.2\% [3.8-9.6\%] and $0.66 \%$ [0.29-1.0\%]; and region 7, 11.0\% [7.7-15.0\%] and 1.7\% [0.92-2.6\%]. The risk factors (odds ratio, OR) associated with positive herds were: purchase of breeding stock (OR $=1.66$ [1.13-2.44]), occurrence of abortions over the last 12 months $(O R=1.81[1.26-2.60])$, and the presence of deer in the farm $(O R=$ 1.56 [1.08-2.27]). Vaccination against brucellosis was a protective factor (OR $=0.38$ [0.19-0.79]). It can be concluded that the compulsory vaccination of heifers, commenced in the 90's, was successful in reducing the prevalence of bovine brucellosis throughout the state and across livestock production systems. The animal health authorities should give priority to controlling the purchase of breeding stock without sanitary assurances and integrate this issue into the educational programmes.

Keywords: cattle, brucellosis, prevalence, risk factors, Minas Gerais, Brazil

\section{INTRODUÇÃO}

Minas Gerais, com sua vocação natural para o agronegócio, tem lugar de destaque na bovinocultura nacional. É o quarto Estado da Federação em extensão territorial, com $586.528 \mathrm{~km}^{2}$. Localiza-se na região Sudeste do Brasil, com 853 municípios (IBGE, 2007b). Possui um total de 349.085 propriedades, onde estão distribuídos 20.991.678 bovinos, representando $10,8 \%$ do rebanho nacional (IBGE, 2006).

Com o segundo maior rebanho bovino do País, em Minas Gerais foram abatidos, em 2007, quase três milhões de cabeças em estabelecimentos sob o Serviço de Inspeção Oficial, representando $8,4 \%$ no País, e correspondendo a quase $600 \mathrm{mil}$ toneladas de carne inspecionada. O Estado exportou em torno de 100 mil toneladas de carne bovina (IBGE, 2007a).

$\mathrm{Na}$ pecuária leiteira, Minas Gerais destaca-se como o principal produtor com participação de $27,8 \%$ da produção total do País (IBGE, 2008). Contudo, o crescimento foi modesto $(7,7 \%)$ no período de 1997 a 2007, apenas acompanhando a média nacional $(7,1 \%)$.

De acordo com Gomes (2001), as diferenças regionais características da bovinocultura brasileira ocorrem tanto em suas finalidades econômicas (pecuária de corte, leite ou mista) como nos índices de produtividade. Uma das principais características da pecuária mineira encontra-se em sua diversidade. Coexistem regiões de produção intensiva e alta produtividade com outras cuja base produtiva é extremamente rudimentar e limitada à subsistência.

A avaliação de distribuição espacial da pecuária bovina mineira mostra que a região do Triângulo/Alto Paranaíba é a mais relevante do Estado neste setor. A região ocupa a primeira posição estadual no rebanho bovino e na produção de leite. Portanto, com grande destaque, é a principal região pecuária do Estado, com significativa vantagem sobre as demais, sendo caracterizada por uma pecuária empresarial, com uso intensivo de tecnologia e sistemas de gerência modernos. Tal característica deve-se à presença, na região, de médias e grandes indústrias de produção de insumos e de beneficiamento da produção pecuária, muitas de atuação nacional e internacional (BDMG, 2002).

A região Sul/Sudoeste apresenta-se como a segunda mais importante para a pecuária estadual, ocupando a segunda posição na produção de leite e a terceira na bovinocultura. $\mathrm{O}$ desenvolvimento da pecuária leiteira nessa região está associado ao clima mais ameno, propício às raças leiteiras, à qualidade de solos $\mathrm{e}$ à proximidade do mercado consumidor de São Paulo. A região foi, até a década de 70 , o principal centro pecuarista do Estado (BDMG, 2002).

Isoladamente, a região Norte figura como a segunda colocada no rebanho bovino estadual, ou $11 \%$ do total. Essa posição deve-se à 
expansão das pastagens plantadas na região, associada à presença de grandes propriedades com explorações extensivas, mas profissionalizadas (BDMG, 2002).

A Zona da Mata aparece como importante bacia leiteira, ocupando a terceira posição no Estado. A região Metropolitana de Belo Horizonte é a menos importante na pecuária bovina, contudo concentra a maior parte do mercado consumidor (BDMG, 2002).

$\mathrm{Na}$ bovinocultura de corte brasileira e mineira predomina o sistema extensivo de produção em regime de pasto. A partir da década passada, porém, a terminação em regime intensivo passou a ganhar importância. Atualmente, mais de três milhões de cabeças são preparadas para abate em regime de confinamento ou semiconfinamento no Brasil.

Em relação ao processamento de carne bovina em Minas Gerais, percebe-se que há uma grande diversidade de tecnologia entre as empresas. De modo geral, as médias e grandes empresas de abate e processamento estão bem posicionadas quanto à tecnologia. Por sua vez, a maior parte dos pequenos frigoríficos, os matadouros municipais - sem falar, é claro, do abate clandestino - encontra-se em estágio tecnológico atrasado e opera em condições precárias, não se enquadrando nas exigências e normas impostas pela inspeção federal (CEPEA, 2009; SEBRAE, 2000).

Não obstante ser o principal produtor de leite do País, o Estado de Minas Gerais não está entre os de maior produtividade. Com 1163 litros/vaca/ano, Minas Gerais está abaixo de Santa Catarina $(2.321 \mathrm{~kg})$, Rio Grande do Sul $(2.221 \mathrm{~kg})$, Paraná $(1.997 \mathrm{~kg})$ e Distrito Federal $(1.816 \mathrm{~kg})$. A produtividade média brasileira é, ainda, muito baixa (IBGE, 2008) quando comparada à de países desenvolvidos, como os Estados Unidos, que alcança 7.953 litros/vaca/ano.

Segundo Gomes (2006), a produção de leite em Minas e no Brasil é caracterizada por pequena quantidade por produtor e pela deficiente qualidade. Entretanto, a maior parte da produção vem do grande produtor, que responde por cerca de $60 \%$ da produção. Segundo esse autor, no sistema de produção de leite predominante no País, a base de alimentação do gado é o pasto.

A indústria de laticínios tem procurado se modernizar e acompanhar as tendências mundiais do setor. A abertura da economia aumentou a concorrência e forçou as empresas a reduzir custos, melhorar a capacidade gerencial e valorizar as estratégias de mercado. De acordo com o SEBRAE (1997), os laticínios com SIF destinam a maior parte do leite recebido para a produção de leite em pó, leite pasteurizado e leite longa vida, enquanto os laticínios sem SIF destinam a maior parte do leite recebido para a produção de queijos tradicionais, em razão de menor exigência de estrutura de produção e maior facilidade de comercialização do produto.

Apesar da modernização da cadeia agroindustrial do leite, no Brasil consome-se um grande volume de leite sem passar pelo sistema de inspeção oficial. Segundo Bandeira (2001), cerca de 40\% da produção nacional de leite fluido, é destinada ao autoconsumo ou vendida nas mais diversas formas de produtos sem inspeção oficial. No período 1994/2000, da produção destinada ao consumo, não passaram pelo sistema de inspeção $34 \%$ do leite fluido, $63 \%$ dos queijos e $41 \%$ dos demais produtos. Neste contexto, a presença endêmica de zoonoses como a brucelose bovina representa alto risco para a saúde pública e diminui a confiança do consumidor nos produtos de origem animal.

Um estudo nacional realizado na década de 1970 pelo Ministério da Agricultura e Secretarias Estaduais de Agricultura (Brasil, 1977) revelou a seguinte soroprevalência de brucelose em bovinos, por regiões: Norte, 4,1\%; Nordeste, 2,5\%; Centro-Oeste, 6,8\%; Sudeste, 7,5\% e Sul, $4,0 \%$. No Estado de Minas Gerais, a prevalência para rebanhos foi de $17,7 \%$ e para fêmeas positivas, $6,3 \%$.

O Instituto Estadual de Saúde Animal (IESA) divulgou, em 1980, o resultado de novo inquérito sorológico, realizado no contexto do Programa Estadual de Brucelose. Do total de 4.096 propriedades testadas, 20,5\% foram soropositivas, e em 25.010 animais testados, 6,6\% (Castro, 1982).

Em 1994, o Instituto Mineiro de Agropecuária (IMA), autoridade sanitária de Minas Gerais, 
implementou um programa de vacinação obrigatória de bezerras de três a oito meses. Em 2003 , esse programa cobriu cerca de $75 \%$ de animais em idade de vacinação.

O presente estudo teve por objetivos estimar a prevalência de focos e de animais soropositivos que permitisse avaliar o impacto do programa de vacinação estadual, identificar os fatores de risco para a brucelose bovina no Estado e fornecer subsídios para a melhor implantação e gestão do Programa Nacional de Controle e Erradicação de Brucelose e Tuberculose (PNCEBT).

\section{MATERIAL E MÉTODOS}

O estudo foi planejado por técnicos do Ministério da Agricultura, Pecuária e Abastecimento, da Universidade de São Paulo e da Universidade de Brasília, em colaboração com o Instituto Mineiro de Agropecuária (IMA). O trabalho de campo foi realizado por técnicos do IMA, no período de abril a setembro de 2002.

Para o conhecimento das diferenças regionais nos parâmetros epidemiológicos da brucelose bovina, o Estado de Minas Gerais foi dividido em sete circuitos produtores de bovinos, levando-se em consideração os diferentes sistemas de produção, práticas de manejo, finalidades de exploração, tamanho médio de rebanhos e sistemas de comercialização. A divisão do Estado em regiões correspondentes a circuitos produtores também levou em conta a capacidade operacional e logística do serviço veterinário oficial do Estado para a realização das atividades de campo, baseando-se nas áreas de atuação de suas unidades regionais.

Em cada circuito produtor, estimou-se a prevalência de propriedades infectadas pela brucelose bovina e de animais soropositivos por meio de um estudo amostral em dois estágios, para detectar focos da doença. No primeiro estágio, sorteou-se, de forma aleatória, um número pré-estabelecido de propriedades com atividade reprodutiva (unidades primárias de amostragem). No segundo, sorteou-se um número pré-estabelecido de fêmeas bovinas com idade igual ou superior a 24 meses (unidades secundárias de amostragem).

Nas propriedades rurais onde existia mais de um rebanho, foi escolhido o rebanho bovino de maior importância econômica, no qual os animais estavam submetidos ao mesmo manejo, ou seja, expostos aos mesmos fatores de risco. A escolha da unidade primária de amostragem foi aleatória, baseada no cadastro de propriedades rurais com atividade reprodutiva de bovinos. A propriedade sorteada que, por motivos vários, não pôde ser visitada, foi substituída por outra, nas proximidades, e com as mesmas características de produção. $\mathrm{O}$ número de propriedades por circuito foi estimado pela fórmula para amostras simples aleatórias proposta por Thrusfield (2007). Os parâmetros adotados para o cálculo foram: nível de confiança de 0,95 , prevalência estimada de 0,25 e erro de 0,05. A capacidade operacional e financeira do serviço veterinário oficial do Estado também foi levada em consideração para a determinação do tamanho da amostra por circuito.

O planejamento amostral para as unidades secundárias visou estimar um número mínimo de animais a serem examinados dentro de cada propriedade de forma a permitir a sua classificação como foco ou não foco de brucelose. Foram amostradas apenas fêmeas com idade igual ou superior a 24 meses. Para tanto, foi utilizado o conceito de sensibilidade e especificidade agregadas (Dohoo et al., 2003). Para efeito dos cálculos foram adotados os valores de $95 \%$ e $99,5 \%$, respectivamente, para a sensibilidade e a especificidade do protocolo de testes utilizado (Fletcher et al., 1998) e 20\% para a prevalência estimada. Nesse processo foi utilizado o programa Herdacc versão 3 e o tamanho da amostra escolhido foi aquele que permitiu valores de sensibilidade e especificidade de rebanho iguais ou superiores a $90 \%$. Assim, nas propriedades com até 99 fêmeas com idade superior a 24 meses, foram amostrados 10 animais, e nas com 100 ou mais fêmeas com idade superior a 24 meses, 15 animais. A escolha das fêmeas dentro das propriedades foi casual sistemática.

O protocolo do sorodiagnóstico foi composto pela triagem com o teste do antígeno acidificado tamponado (Rosa Bengala), seguida do reteste dos positivos com o teste do 2-mercaptoetanol, de acordo com as recomendações do PNCEBT (Brasil, 2006). O sangue (15mL) foi coletado por punção da veia jugular com agulha descartável estéril em tubo com vácuo, previamente 
identificado. Os soros, armazenados em microtubos de plástico, foram mantidos a $-20^{\circ} \mathrm{C}$ até a realização dos testes. Os testes sorológicos foram realizados no laboratório do IMA, em Belo Horizonte, MG.

A propriedade foi considerada positiva quando se detectou pelo menos um animal positivo. As propriedades que apresentaram animais com resultado sorológico inconclusivo, com ausência de positivos, foram classificadas como suspeitas e excluídas das análises. O mesmo tratamento foi dado aos animais com resultados sorológicos inconclusivos.

O planejamento amostral permitiu determinar as prevalências de focos e de fêmeas adultas $(\geq 24 \mathrm{~m})$ soropositivas para brucelose no Estado e

\section{$P_{2}=\frac{\text { fêmeas } \geq 24 \text { meses na propriedade }}{\text { fêmeas } \geq 24 \text { meses amostradas na propriedade }}$}

$\mathrm{Na}$ expressão acima, o primeiro termo refere-se ao peso de cada animal no cálculo das prevalências de animais dentro das regiões.

Em cada propriedade amostrada, além da coleta de sangue para a sorologia, foi também aplicado um questionário epidemiológico, elaborado para obter informações sobre o tipo de exploração e as práticas de manejo empregadas, de forma a permitir a realização do estudo de fatores de risco associados à presença da brucelose. Nesse estudo, as variáveis analisadas foram: tipo ou sistema de exploração (carne, leite e misto), tipo de criação (confinado, semiconfinado, extensivo), uso de inseminação artificial, raças predominantes, número de vacas com idade superior a 24 meses, número de bovinos na propriedade, presença de outras espécies domésticas, presença de animais silvestres, destino da placenta e dos fetos abortados, compra e venda de animais, vacinação contra brucelose, abate de animais na propriedade, aluguel de pastos, pastos comuns com outras propriedades, pastos alagados, piquete de parição e assistência veterinária. também nos circuitos produtores. Os cálculos das prevalências aparentes e os respectivos intervalos de confiança foram realizados conforme preconizado por Dean et al. (1994). Os cálculos das prevalências de focos e de animais e de prevalências de animais dentro de região foram feitos de forma ponderada (Dohoo et al., 2003).

O peso de cada propriedade no cálculo da prevalência de focos no Estado foi dado por

$$
P_{1}=\frac{\text { propriedades na região }}{\text { propriedades amostradas na região }}
$$

O peso de cada animal no cálculo da prevalência de animais no Estado foi dado por

fêmeas $\geq 24$ meses na região
As variáveis foram organizadas de modo a se apresentarem em escala crescente de risco. Quando necessário, realizou-se a recategorização dessas variáveis. A categoria de menor risco foi considerada como base para a comparação das demais. As variáveis quantitativas foram categorizadas em percentis.

Foi feita uma primeira análise exploratória dos dados (univariada) para seleção daquelas com $\mathrm{p} \leq 0,20$ para o teste do $\chi^{2}$ ou exato de Fisher e, subseqüente, oferecimento dessas à regressão logística. Os cálculos foram realizados com o auxílio do programa SPSS, versão 9.0.

Todas as informações geradas pelo trabalho de campo e de laboratório foram inseridas em um banco de dados específico, utilizado nas análises epidemiológicas.

\section{RESULTADOS E DISCUSSÃO}

O Estado foi dividido em sete circuitos produtores (Fig. 1). A Tab. 1 apresenta um resumo dos dados censitários e da amostra estudada em cada um dos circuitos produtores. 


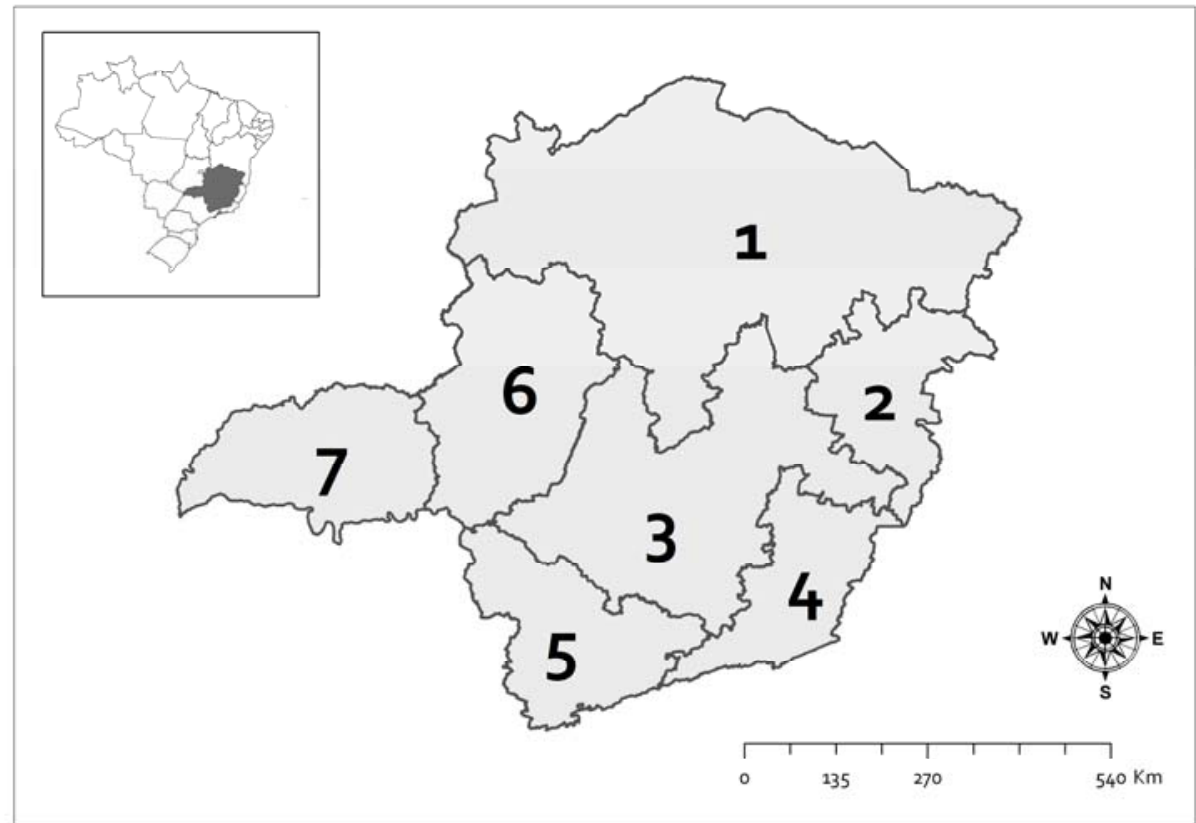

Figura 1. Mapa do Estado de Minas Gerais com a divisão em circuitos produtores. No detalhe, a localização do Estado de Minas Gerais no Brasil.

Tabela 1. Dados censitários da população bovina do Estado de Minas Gerais em 2002, segundo o circuito produtor

\begin{tabular}{lcccc} 
Circuito produtor-região & $\begin{array}{c}\text { Total de } \\
\text { propriedades } \\
\text { com atividade } \\
\text { reprodutiva }\end{array}$ & $\begin{array}{c}\text { Propriedades } \\
\text { amostradas }\end{array}$ & $\begin{array}{c}\text { Total de } \\
\text { fêmeas com } \\
\text { idade } \geq 24\end{array}$ & $\begin{array}{c}\text { Fêmeas } \\
\text { amostradas }\end{array}$ \\
\hline 1- Noroeste, Norte e Nordeste & 60.547 & 318 & 1.977 .439 & 3.178 \\
2- Leste & 20.472 & 307 & 824.916 & 2.898 \\
3- Central & 73.932 & 326 & 1.577 .485 & 2.972 \\
4- Zona da Mata & 43.688 & 323 & 597.115 & 2.619 \\
5- Sul e Sudoeste & 55.602 & 316 & 988.230 & 2.744 \\
6- Alto Paranaíba & 25.568 & 305 & 1.039 .756 & 2.909 \\
7- Triângulo Mineiro & 20.921 & 309 & 1.599 .449 & 3.323 \\
Total & 300.730 & 2.204 & 8.604 .390 & 20.643 \\
\hline
\end{tabular}

Fonte: Instituto Mineiro de Agropecuária.

$\mathrm{Na}$ Tab. 2, são apresentados os resultados de prevalência de focos no Estado e nos circuitos produtores. A prevalência de focos por tipo de exploração da propriedade é apresentada na Tab. 3 e, a prevalência de animais, na Tab. 4.

Na Tab. 5 apresentam-se os resultados da análise univariada e na Tab. 6, o modelo final da regressão logística.

No Estado de Minas Gerais, a prevalência de focos de brucelose foi estimada em $6,0 \%$ [5,0-
7,1\%]. A prevalência de focos no Estado foi relativamente homogênea entre os circuitos, embora o circuito produtor 7 (região do Triângulo Mineiro) tenha apresentado prevalência de focos de 11,0\% [7,7-15,0\%], estatisticamente mais elevada que os circuitos $1 \mathrm{e}$ 5 (Tab. 2). A prevalência de focos estratificada por tipo de produção ficou caracterizada por uma situação homogênea (Tab. 3), sem diferenças estatisticamente significativas, o que pode reforçar a idéia de que a estratégia vacinal está sendo aplicada com eficácia. 
Tabela 2. Prevalência de focos de brucelose bovina na propriedade, segundo o circuito produtor, no Estado de Minas Gerais, 2002

\begin{tabular}{|c|c|c|c|c|}
\hline \multirow{2}{*}{ Circuito produtor } & \multicolumn{2}{|c|}{ Propriedades } & \multirow{2}{*}{$\begin{array}{c}\text { Prevalência } \\
(\%)\end{array}$} & \multirow{2}{*}{ IC $(95 \%)$} \\
\hline & Testadas & Positivas & & \\
\hline 1- Noroeste, Norte e Nordeste & 318 & 15 & 4,72 & {$[2,66-7,66]$} \\
\hline 2- Leste & 307 & 22 & 7,17 & {$[4,55-10,65]$} \\
\hline 3- Central & 326 & 22 & 6,75 & {$[4,28-10,04]$} \\
\hline 4- Zona da Mata & 323 & 21 & 6,50 & {$[4,07-9,77]$} \\
\hline 5- Sul e Sudoeste & 316 & 12 & 3,80 & {$[1,98-6,54]$} \\
\hline 6- Alto Paranaíba & 305 & 19 & 6,23 & {$[3,79-9,56]$} \\
\hline 7- Triângulo Mineiro & 309 & 34 & 11,00 & {$[7,74-15,04]$} \\
\hline Estado & 2.204 & 145 & 6,04 & {$[4,98-7,10]$} \\
\hline
\end{tabular}

IC: intervalo de confiança.

Tabela 3. Prevalência (Prev) de focos de brucelose bovina estratificada por tipo de exploração, segundo o circuito produtor, no Estado de Minas Gerais

\begin{tabular}{|c|c|c|c|c|c|c|}
\hline \multirow{2}{*}{ Circuito produtor } & \multicolumn{2}{|c|}{ Corte } & \multicolumn{2}{|c|}{ Leite } & \multicolumn{2}{|c|}{ Misto } \\
\hline & Prev (\%) & IC (95\%) & $\overline{\text { Prev (\%) }}$ & IC $(95 \%)$ & Prev (\%) & IC $(95 \%)$ \\
\hline 1- Noroeste, Norte e Nordeste & 6,33 & {$[2,09-14,15]$} & 4,04 & {$[1,11-10,02]$} & 4,29 & {$[1,59-9,09]$} \\
\hline 2- Leste & 9,52 & {$[1,17-30,37]$} & 2,48 & {$[0,51-7,07]$} & 10,30 & {$[6,12-15,98]$} \\
\hline 3- Central & 5,26 & {$[0,13-26,03]$} & 6,08 & {$[3,27-10,16]$} & 8,70 & {$[3,83-16,42]$} \\
\hline 4- Zona da Mata & 12,50 & {$[1,55-38,35]$} & 6,75 & {$[3,91-10,73]$} & 4,29 & {$[0,89-12,02]$} \\
\hline 5- Sul e Sudoeste & 20,00 & {$[2,52-55,61]$} & 3,59 & {$[1,45-7,26]$} & 2,75 & {$[0,57-7,83]$} \\
\hline 6- Alto Paranaíba & 0,00 & {$[0,00-21,80]$} & 5,97 & {$[3,12-10,20]$} & 7,86 & {$[3,22-15,54]$} \\
\hline 7- Triângulo Mineiro & 9,37 & {$[3,52-19,30]$} & 10,97 & {$[6,52-16,98]$} & 12,22 & {$[6,26-20,82]$} \\
\hline
\end{tabular}

IC: intervalo de confiança.

Tabela 4. Prevalência de bovinos sororreagentes para brucelose segundo o circuito produtor no Estado de Minas Gerais

\begin{tabular}{|c|c|c|c|c|}
\hline \multirow{2}{*}{ Circuito produtor } & \multicolumn{2}{|c|}{ Animais } & \multirow{2}{*}{$\begin{array}{c}\text { Prevalência } \\
(\%)\end{array}$} & \multirow{2}{*}{$\mathrm{IC}(95 \%)$} \\
\hline & Testados & Positivos & & \\
\hline 1- Noroeste, Norte e Nordeste & 3.178 & 30 & 0,82 & {$[0,06-1,58]$} \\
\hline 2- Leste & 2.898 & 43 & 1,18 & {$[0,53-1,83]$} \\
\hline 3- Central & 2.972 & 38 & 1,46 & {$[0,47-2,45]$} \\
\hline 4- Zona da Mata & 2.619 & 30 & 1,06 & {$[0,39-1,73]$} \\
\hline 5- Sul e Sudoeste & 2.744 & 15 & 0,40 & {$[0,11-0,69]$} \\
\hline 6- Alto Paranaíba & 2.909 & 23 & 0,66 & {$[0,29-1,02]$} \\
\hline 7- Triângulo Mineiro & 3.323 & 47 & 1,74 & {$[0,92-2,57]$} \\
\hline Total & 20.643 & 226 & 1,09 & {$[0,78-1,41]$} \\
\hline
\end{tabular}

IC: intervalo de confiança. 
Tabela 5. Resultados da análise univariada dos possíveis fatores de risco para brucelose bovina no Estado de Minas Gerais, para variáveis com $\mathrm{P} \leq 0,20$

\begin{tabular}{|c|c|c|c|}
\hline Variável & Expostos/focos & Expostos/não focos & $\mathrm{p}$ \\
\hline \multicolumn{4}{|l|}{ Tipo de criação } \\
\hline Confinada & $03 / 145$ & $23 / 2.059$ & \\
\hline Semiconfinada & $73 / 145$ & $793 / 2.059$ & \\
\hline Extensiva & $69 / 145$ & $1.243 / 2.059$ & 0,008 \\
\hline \multicolumn{4}{|l|}{$\mathrm{N}^{\mathrm{o}}$ de ordenhas } \\
\hline 1 ordenha & $13 / 145$ & $176 / 2.059$ & \\
\hline 2 ou 3 ordenhas & $73 / 145$ & $1.318 / 2.059$ & \\
\hline Não ordenha & $59 / 145$ & $565 / 2.059$ & 0,002 \\
\hline \multicolumn{4}{|l|}{ Raça de bovinos predominante } \\
\hline Zebu & $25 / 145$ & $246 / 2.058$ & \\
\hline Europeu de aptidão leiteira & $12 / 145$ & $190 / 2.058$ & \\
\hline Mestiço & $83 / 145$ & $1.354 / 2.058$ & \\
\hline Outras raças & $25 / 145$ & $268 / 2.058$ & 0,088 \\
\hline \multicolumn{4}{|l|}{ Cria equinos } \\
\hline Não & $8 / 145$ & $242 / 2.059$ & \\
\hline Sim & $137 / 145$ & $1.817 / 2.059$ & 0,022 \\
\hline \multicolumn{4}{|l|}{ Cães na propriedade } \\
\hline Ausência & $13 / 145$ & $329 / 2.059$ & \\
\hline Presença & $132 / 145$ & $1.730 / 2.059$ & 0,024 \\
\hline \multicolumn{4}{|l|}{ Cervídeos na propriedade } \\
\hline Ausência & $92 / 145$ & $1.573 / 2.059$ & \\
\hline Presença & $53 / 145$ & $486 / 2.059$ & $<0,001$ \\
\hline \multicolumn{4}{|l|}{ Capivaras na propriedade } \\
\hline Ausência & $101 / 145$ & $1.543 / 2.059$ & \\
\hline Presença & $44 / 145$ & $516 / 2.059$ & 0,158 \\
\hline \multicolumn{4}{|c|}{ Ocorrência de aborto nos últimos 12 meses } \\
\hline Não & $81 / 145$ & $1.466 / 2.059$ & \\
\hline Sim & $55 / 145$ & $487 / 2.059$ & \\
\hline Não sabe informar & $9 / 145$ & $106 / 2.059$ & $<0,001$ \\
\hline \multicolumn{4}{|c|}{ Realiza testes para diagnóstico de brucelose } \\
\hline Não & $106 / 145$ & $1.670 / 2.059$ & \\
\hline Sim & $39 / 145$ & $389 / 2.059$ & 0,019 \\
\hline \multicolumn{4}{|c|}{ Compra de fêmeas ou machos reprodutores } \\
\hline Não & $42 / 145$ & $907 / 2.059$ & \\
\hline Sim & $103 / 145$ & $1.152 / 2.059$ & $<0,001$ \\
\hline \multicolumn{4}{|c|}{ Venda de fêmeas ou machos reprodutores } \\
\hline Não & $81 / 145$ & $1.305 / 2.059$ & \\
\hline Sim & $64 / 145$ & $754 / 2059$ & 0,07 \\
\hline \multicolumn{4}{|l|}{ Vacina contra brucelose } \\
\hline Não & $137 / 145$ & $907 / 2.059$ & \\
\hline Sim & $8 / 145$ & $1.152 / 2.059$ & 0,002 \\
\hline
\end{tabular}

Tabela 6. Modelo final da regressão logística multivariada de fatores de risco (odds ratio) para brucelose bovina no Estado de Minas Gerais

\begin{tabular}{lccc}
\hline Variável & Odds ratio & IC (95\%) & $\mathrm{p}$ \\
\hline Vacina fêmeas entre 3 e 8 meses de idade & 0,38 & {$[0,19-0,79]$} & 0,009 \\
Presença de cervídeos na propriedade & 1,56 & {$[1,08-2,27]$} & 0,019 \\
Compra fêmeas ou machos reprodutores & 1,66 & {$[1,13-2,44]$} & 0,010 \\
Ocorrência de aborto nos últimos 12 meses & 1,81 & {$[1,26-2,60]$} & 0,001 \\
\hline
\end{tabular}

IC: intervalo de confiança. 
A maior prevalência de focos e de animais encontrada no Triângulo Mineiro, onde se iniciou o programa de vacinação, pode ser resultado do impacto do intenso trânsito de animais e da alta densidade animal que caracteriza essa região. O Triângulo Mineiro abriga $18.6 \%$ do total de fêmeas bovinas com idade $\geq 24$ meses do Estado, menor apenas que o circuito 1, detentor da maior área (Norte, Noroeste e Nordeste), com 23,0\% (Tab. 1).

A menor prevalência de focos no Estado foi encontrada no circuito 5 (regiões Sul e Sudoeste), onde predomina a pecuária leiteira, e no 1 (Noroeste, Norte e Nordeste), com 3,8\% [2,0-6,5\%] e 4,7\% [2,7-7,7\%], respectivamente (Tab. 2). Na região Sul/Sudoeste, bacia leiteira mais tradicional de Minas Gerais, verificou-se a menor prevalência. Essas diferenças regionais devem ser analisadas de forma conservadora, uma vez que os intervalos de confiança se sobrepõem, não havendo, portanto, diferenças estatisticamente significativas entre regiões.

A prevalência de animais soropositivos para brucelose no Estado de Minas Gerais foi de 1,1\% [0,78-1,4\%] (Tab. 4). Os circuitos com maior prevalência foram o 7 e o $3,1,7 \%$ [0,92-2,6\%] e $1,5 \%$ [0,47-2,4\%], respectivamente (Tab. 2 e 4). $\mathrm{O}$ circuito $7 \mathrm{faz}$ fronteira com os Estados de Mato Grosso do Sul, São Paulo e Goiás. Como existe intensa movimentação de animais entre esses Estados e o Estado de Minas Gerais, é natural supor que nesse circuito a situação epidemiológica da brucelose seja influenciada pela situação existente nesses Estados.

Estes resultados mostram redução acentuada na prevalência da infecção no Estado nos últimos 30 anos, quando comparado com o histórico divulgado em 1980 pelo Instituto Estadual de Saúde Animal (IESA), 20,5\% de focos e 6,6\% de animais soropositivos (Castro, 1982), ou, ainda, se comparado aos resultados do inquérito nacional divulgado na década de 1970, quando a prevalência para rebanhos positivos foi de 17,7\%, e para fêmeas positivas, 6,3\% (Brasil, 1977). A diminuição de prevalência verificada constitui um indicativo de que o programa estadual de vacinação sistemática de bezerras, iniciado na década de 1990, está colhendo frutos.

O modelo final de regressão logística indicou que nas fazendas que compram animais para reprodução há maior chance de ocorrência de brucelose bovina (Tab. 6). O verdadeiro problema não é a introdução de animais, prática rotineira nos rebanhos bovinos, mas sim a aquisição de animais sem a realização de testes ou sem o conhecimento da condição sanitária do rebanho de origem. A compra de animais infectados é amplamente reportada como o principal fator de introdução de brucelose em rebanhos livres (Van Wavern, 1960; Nicoletti, 1980). Este resultado mostra a necessidade de conscientizar os criadores no sentido de exigir teste de diagnóstico antes de comprar animais, ou de adquirir animais apenas de rebanhos certificados como livres da doença. A fiscalização sanitária deve considerar que este é um fator prioritário nas suas ações preventivas.

A associação de focos com a presença de cervídeos na propriedade foi observada, mas é de difícil interpretação em um estudo transversal. Merece ser investigada de forma mais aprofundada em estudos longitudinais e mais dirigidos a variáveis dessa complexidade. Seria necessário caracterizar melhor a forma como se dá o contato entre bovinos e cervídeos e se estes estão efetivamente atuando como reservatórios da brucelose bovina. Cervídeos e outros ungulados silvestres têm sido descritos como reservatórios de $B$. abortus para bovinos domésticos (Paulin e Ferreira Neto, 2003).

A incidência de abortos nos últimos 12 meses também ocorreu com maior frequência em rebanhos infectados, confirmando que, mesmo com prevalências mais baixas, essa enfermidade ainda é responsável por perdas produtivas.

A análise também demonstrou que as propriedades que vacinavam tinham menor probabilidade de estar infectadas do que aquelas que não cumpriam essa norma sanitária. Este resultado mostra que a vacina comercializada no Brasil realmente protege em situação de campo e reforça a ideia de que o programa de vacinação tem sido eficaz, devendo servir de estímulo para outras unidades da Federação implementarem a estratégia de vacinação proposta pelo PNCEBT.

É importante ressaltar que, neste estudo, a presença de brucelose em Minas Gerais não se mostrou associada a características produtivas do rebanho, como, por exemplo, aptidão para leite ou para corte, criação intensiva ou extensiva, 
predominância de bovinos europeus ou de mestiços e nem mesmo tamanho do rebanho. Isto significa que as autoridades sanitárias terão dificuldade em estabelecer medidas sanitárias muito seletivas, dirigidas a determinado tipo de exploração do rebanho ou a um sistema de produção. Consequentemente, a manutenção e intensificação do programa obrigatório de vacinação parece ser uma prioridade. A certificação de propriedades livres de brucelose, preconizada pelo PNCEBT, deverá evoluir de forma favorável, tendo em vista a relativamente baixa prevalência encontrada. Na medida que o número de propriedades livres aumentar, os criadores terão maior oferta de animais reprodutores procedentes de rebanhos certificados, o que, segundo os resultados deste estudo, deverá contribuir para a prevenção e erradicação da brucelose bovina. Este é um ponto a ser considerado pelo PNCEBT, cujo regulamento já prevê que propriedades livres sejam, no futuro, obrigadas a adquirir animais apenas de outras propriedades com a mesma condição sanitária.

Recomenda-se fiscalizar e desencorajar a compra de reprodutores sem teste para brucelose ou de propriedades sem controle da doença; fazer avançar a certificação de propriedades livres de forma a promover a segurança sanitária dos produtos de origem animal e aumentar a oferta de fêmeas e machos para reprodução livres de brucelose; continuar o programa de vacinação em todo o Estado, sustentando coberturas vacinais de bezerras em, pelo menos, $80 \%$, com especial atenção a regiões de intenso trânsito animal e alta densidade de animais, como o Triângulo Mineiro.

\section{AGRADECIMENTOS}

À FAPESP, ao CNPq, ao IMA e ao MAPA pelo apoio financeiro.

\section{REFERÊNCIAS BIBLIOGRÁFICAS}

BDMG. BANCO DO ESTADO DE MINAS GERAIS. Minas Gerais do Século XXI: transformando o desenvolvimento da agropecuária. Belo Horizonte: BDMG, 2002. 224p. Disponível em: http://bdmg.mg.gov.br/estudo_cadernos.asp>. Acessado em: 20 dez. 2008.
BANDEIRA, A. A melhoria da qualidade e a modernização da pecuária leiteira nacional. In: GOMES, A.T.; LEITE, J.L.B.; CARNEIRO, A.V. (Ed.). O agronegócio do leite no Brasil. Juiz de Fora: Embrapa Gado de Leite, 2001. p.89-100.

BRASIL. Ministério da Agricultura e Abastecimento. Diagnóstico de saúde animal, Brasília, 1977. 735p.

BRASIL. Ministério de Agricultura, Pecuária e Abastecimento. Programa Nacional de Controle e Erradicação da Brucelose e da Tuberculose Animal (PNCEBT): Manual técnico. Brasília, 2006. 184p.

CASTRO, D. Prevalência da brucelose nas áreas trabalhadas pelo IESA em Minas Gerais-1980. Bol. IESA, n.1, p.1-12, 1982.

CEPEA (Centro de Estudos Avançados em Economia Aplicada). Cadeia agroindustrial do boi. Disponível em: $<$ http://www.cepea.esalq.usp.br>. Acessado em: 10 jan. 2009.

DEAN, A.G.; DEAN, J.A.; COLOMBIER, D. et al. Epi-Info, version 6: A word processing database and statistics program for epidemiology on microcomputers. Atlanta: CDC, 1994. 601p.

DOHOO, I.; MARTIN, W.; STRYHN, H. Veterinary epidemiologic research. Charlottetown, Canadá: Atlantic Veterinary College, 2003. 706p.

FLETCHER, R.H.; FLETCHER, S.W.; WAGNER, E.H. Clinical epidemiology: The essentials. 2.ed. Baltimore: Williams \& Wilkins, 1998. 246p.

GOMES, S.T. Cadeia produtiva do leite. In: VILELA, D.; CARVALHO, L.A.; MARTINS, C.E. et al. (Ed.). Sustentabilidade da pecuária de leite no Brasil: Qualidade e segurança alimentar. Juiz de Fora: Embrapa Gado de Leite, 2001. p.109-120.

GOMES, S.T. Diagnóstico da pecuária leiteira do Estado de Minas Gerais em 2005: Relatório de pesquisa. Belo Horizonte: FAEMG, 2006. $156 \mathrm{p}$.

IBGE. Rio de Janeiro, 2007. Disponível em: $<$ http:www.sidra.ibge.gov.br $>$ Acessado em: 10 mar. 2008.

IBGE. Censo agropecuário 2006. Disponível em: $<$ http://www.ibge.gov.br/home/estatistica/econo 
mia/agropecuaria/censoagro/2006/agropecuario.p df $>$. Acessado em: 3 nov. 2008.

IBGE. Contagem da população. 2007b. Disponível em: <http://www.ibge.gov.br/home/ estatistica/populacao/contagem2007/contagem.p df)>. Acessado em: 3 nov. 2008.

IBGE. Pesquisa da Pecuária Municipal, 1997 a 2007. Disponível em: $<$ http://www.ibge.gov.br/home/estatistica/econo mia/ppm/2007/ppm2007.pdf>. Acessado em: 20 nov. 2008.

NICOLETTI, P. The epidemiology of bovine brucellosis. Adv. Vet. Sci. Comp. Med., v.24, p.69-98, 1980.
PAULIN, L.M.; FERREIRA NETO, J.S. $O$ combate à brucelose bovina: Situação brasileira. Jaboticabal: Funep, 2003. 154p.

SEBRAE. Diagnóstico da indústria de laticínios do Estado de Minas Gerais. Belo Horizonte, 1997. 270p.

SEBRAE. Estudo da eficiência econômica $e$ competitividade da cadeia agroindustrial da pecuária de corte no Brasil. Brasília: IEL/CNA/SEBRAE, 2000. 414p.

THRUSFIELD, M. Veterinary epidemiology. 3.ed. Oxford: Blackwell Science, 2007. 610p.

VAN WAVERN, G.M. The control of brucellosis in the Netherlands. Vet. Rec., v.72, p.928, 1960. 